\title{
MECHANICAL, DYNAMIC MECHANICAL AND MORPHOLOGICAL PROPERTIES OF COMPOSITES BASED ON RECYCLED POLYSTYRENE FILLED WITH WOOD FLOUR WASTES
}

\author{
Matheus Poletto ${ }^{1,4}$
}

\begin{abstract}
In this work, the potential for usage recycled polystyrene and wood flour wastes as materials for development wood plastic composites was evaluated. The effects of wood flour loading and coupling agent addition on the mechanical, dynamic mechanical and morphological properties of polystyrene wood flour composites were examined. The results showed that the mechanical properties decreased with the wood flour loading. However, an improvement in composite compatibility was observed when the coupling agent was used resulting in the increase of mechanical and dynamic mechanical properties. A morphological study demonstrates the positive effect in the interfacial adhesion between filler and matrix caused by the coupling agent addition. Based on the findings of this work, both waste materials can be used for development composites with higher performance.
\end{abstract}

Keywords: Coupling agent, damping factor, impact strength, interfacial adhesion, stiffness, storage modulus tensile modulus.

\section{INTRODUCTION}

During the last decades, both ecological and economic interests have resulted in a more intensive utilization of natural and recycled materials for development composites (Kim et al. 2007, Najafi 2013, Ou et al. 2014, Nafchi et al. 2015, Kord et al. 2016). Issues such as recyclability and environmental safety have become important for introduce composites materials in several markets (AlMaadeed et al. 2014a, Kord et al. 2016). An important group of these materials is represented by lignocellulosic fibers reinforced thermoplastic polymers. Wood plastic composites are one of the most attractive composites because it offers a favorable method to effectively recycled polymers and also use the forest and agricultural by-products to prepare valuable composites (Kim et al. 2007, AlMaadeed et al. 2014a, Liu et al. 2014).

Wood plastic composites have advantages in terms of easy manufacture process, environmental and healthy safety, biodegradability and low cost when compared with thermoplastic polymers reinforced with inorganic fillers (Khonsari et al. 2015, Teuber et al. 2016, Tufan et al. 2016). In addition, they have been widely used as automotive parts, building applications and consumer products (Hong et al. 2014, Eshraghi et al. 2016, Tufan et al. 2016, Teuber et al. 2016). However, most thermoplastics are hydrophobic while wood flour is hydrophilic. The hydrophilic wood flour is generally incompatible with hydrophobic thermoplastics (Hong et al. 2014, Güleç et al. 2017). The incompatibility between filler and polymer matrix results in composites with lower mechanical properties (Spoljaric et al. 2009, Hong et al. 2014, Khonsari et al. 2015). 
To successfully prepare a high performance wood plastic composite, the compatibility between thermoplastic polymer and wood flour are normally improved using coupling agents, such as, graft copolymers (Hong et al. 2014). These graft copolymers was proved to be one of the most effective measured to improve the compatibility by chemically enhancing the interfacial interaction between the polymer matrix and lignocellulosic fibers. The most commonly graft copolymers used are maleated polyolefins, because these coupling agents can afford strong interfacial interaction between thermoplastics and natural fiber by the esterification reaction between the maleic anhydride and the hydroxyl of the natural lignocellulosic fibers (Kim et al. 2007, Hong et al. 2014, Güleç et al. 2017).

In this paper, a graft copolymer composed of poly (styrene-co-maleic anhydride) is used to synergistically compatibilize the recycled expanded polystyrene (rPS)/ wood flour composites. How the coupling agent used affected the mechanical properties, morphology and dynamic mechanical properties of the rPS/ wood flour composites were investigated.

\section{MATERIALS AND METHODS}

\section{Materials}

The expanded polystyrene wastes were obtained from a sorting unit called Associação de Recicladores Serrano, Caxias do Sul, Brazil. It had a melt flow index of $20 \mathrm{~g} / 10 \mathrm{~min}\left(200^{\circ} \mathrm{C} / 5 \mathrm{~kg}\right)$. Wood flour of Pinus elliottii was obtained from Madarco S.A., Caxias do Sul, Brazil, with a particle size range of 53-105 $\mu \mathrm{m}$. The wood flour waste used in this study was not subject to any kind of preliminary chemical treatment. The poly(styrene-co-maleic anhydride) oligomer, SMA, supplied by Sartomer Co., Exton/USA used as the coupling agent was SMA2000, containing $30 \mathrm{wt} \%$ of maleic anhydride groups and with a weight average molecular weight of $7500 \mathrm{~g} / \mathrm{mol}$. The amount of coupling agent incorporated was $2 \mathrm{wt} \%$.

\section{Composite preparation}

The wood flour was previously dried in an oven at $105^{\circ} \mathrm{C}$ for $24 \mathrm{~h}$ before use it in composite formulations. Samples with 20 and $40 \mathrm{wt} \%$ of wood flour, with and without $2 \mathrm{wt} \%$ of SMA2000, and rPS were processed in a co-rotating twin-screw extruder at $200 \mathrm{rpm}$. The nine barrel temperature zones were controlled at between $160^{\circ} \mathrm{C}$ and $190^{\circ} \mathrm{C}$. Specimens for mechanical tests were injection molded at a barrel temperature of $180^{\circ} \mathrm{C}$ and mold temperature of $40 \pm 2^{\circ} \mathrm{C}$. The composites were denoted by the symbols U200, S202, etc. In these notations, the first letter denotes the coupling agent used, $\mathrm{U}$ - untreated and S - treated with SMA2000. The first and second digits together denote the weight percentage of the wood flour and the third digit denotes the amount of coupling agent used.

\section{Mechanical properties measurements}

The tensile tests were conducted according to ASTM D638 at $5 \mathrm{~mm} \cdot \mathrm{min}^{-1}$, with a $50-\mathrm{mm}$ extensometer, using an EMIC DL 3000 analyzer. The flexural tests were performed on the same analyzer according to ASTM D790 at a cross-head speed of $1,5 \mathrm{~mm} \cdot \mathrm{min}^{-1}$. Izod impact strength was measured with a CEAST Resil 25 pendulum using unnotched specimens according to ASTM D256. Each test value was calculated as the average of at least five independent measurements.

\section{Morphological study}

Studies on the morphology of the composites were carried out using a SHIMADZU Superscan SS550 , scanning electron microscope (SEM). The cryo-fracture surface specimens were sputter-coated with gold before analysis in order to eliminate electron charging.

\section{Dynamic mechanical analysis}

Specimens of rPS and composites, with dimensions of 50 x $13 \times 3,5 \mathrm{~mm}$, were subjected to dynamic mechanical testing using an Anton Paar Physica MCR 101 oscillatory rheometer operating in DMA 
mode. The measurements were carried out in the torsion mode of the equipment and the corresponding viscoelastic properties were determined as a function of temperature. The temperature range used in the experiment was 30 to $140^{\circ} \mathrm{C}$, with a heating rate of $3^{\circ} \mathrm{C} / \mathrm{min}$, under nitrogen flow. The samples were scanned at a fixed frequency of $1 \mathrm{~Hz}$, with a dynamic strain of $0,1 \%$.

\section{RESULTS AND DISCUSSIONS}

\section{Mechanical properties}

Considering practical applications, composite mechanical properties are of major importance (Nachtigall et al. 2007, Punyamurthy et al. 2014). The tensile strength is one the most important mechanical properties that helps to selected a composite material for several applications (Punyamurthy et al. 2014). As presented in Table 1, the tensile strength of composites without coupling agent decreased when compared to polymer matrix, due to the weak interfacial adhesion caused by the low compatibility between hydrophilic wood flour and hydrophobic polystyrene. The incompatibility between the two components results in poor stress transfer from the rPS to filler, and thus the composites failure at lower tensile strength. The tensile strain also reduces with wood flour loading with indicates that the composite becomes more brittle with the wood flour addition. In general, the flexural properties presented the same behavior observed for tensile properties. However, the flexural strength of composites with coupling agent significantly increases when compared with composites without SMA2000. The improvement in flexural strength for composites with $20 \mathrm{wt} \%$ and $40 \mathrm{wt} \%$ of wood flour correspond to $10 \%$ and $20 \%$, respectively.

The presence of coupling agent in composite formulations caused an increase in tensile and flexural properties. According to the classical theory of mechanics, load applied to a particle-reinforced composite is transferred from the matrix to the particles by shear stress along the particle-matrix interface (Ou et al. 2014). The incorporation of SMA2000 promotes the dispersion of wood flour in the rPS matrix and improved the interfacial interaction between wood flour and matrix, as can be seen in Figure 3. As a consequence, the stress transfer from matrix to the filler is more efficient, leading to a significant improvement in the composite mechanical properties (Güleç et al. 2017). An improvement on the tensile and flexural strength after addition of maleated anhydride polyethylene as also verified by Turku et al. (2017) in wood plastic composites manufactured from recycled plastic blends (Turku et al. 2017). In addition, the smaller wood flour particles used, with particle size between 53 and $105 \mu \mathrm{m}$, provide a higher specific surface area, causing better stress transfer from the matrix to the wood flour increasing the mechanical properties.

Table 1. Mechanical properties of the samples studied.

\begin{tabular}{|l|c|c|c|c|c|c|}
\hline Sample & $\begin{array}{c}\text { Tensile } \\
\text { strength } \\
\text { (MPa) }\end{array}$ & $\begin{array}{c}\text { Tensile } \\
\text { strain } \\
(\%)\end{array}$ & $\begin{array}{c}\text { Tensile } \\
\text { modulus } \\
\text { (MPa) }\end{array}$ & $\begin{array}{c}\text { Flexural } \\
\text { strength } \\
\text { (MPa) }\end{array}$ & $\begin{array}{c}\text { Flexural } \\
\text { strain } \\
(\mathbf{\%})\end{array}$ & $\begin{array}{c}\text { Flexural } \\
\text { modulus } \\
\text { (MPa) }\end{array}$ \\
\hline rPS & $37,23 \pm 0,57$ & $1,14 \pm 0,01$ & $3494,1 \pm 64,2$ & $46,10 \pm 1,53$ & $1,56 \pm 0,06$ & $3315,3 \pm 189,5$ \\
\hline U200 & $34,88 \pm 0,61$ & $0,85 \pm 0,06$ & $4208,1 \pm 33,9$ & $49,00 \pm 1,68$ & $1,22 \pm 0,04$ & $4072,2 \pm 21,9$ \\
\hline U400 & $35,39 \pm 1,53$ & $0,54 \pm 0,06$ & $5615,1 \pm 115,9$ & $46,51 \pm 1,75$ & $0,89 \pm 0,04$ & $5725,8 \pm 85,6$ \\
S202 & $36,43 \pm 0,60$ & $0,44 \pm 0,14$ & $4426,3 \pm 126,1$ & $54,12 \pm 1,66$ & $1,28 \pm 0,04$ & $4166,6 \pm 39,7$ \\
\hline S402 & $37,66 \pm 0,80$ & $0,43 \pm 0,11$ & $5809,8 \pm 72,2$ & $56,04 \pm 1,98$ & $1,08 \pm 0,04$ & $5745,0 \pm 94,3$ \\
\hline
\end{tabular}

The composite modulus is often a property of particular interest (Punyamurthy et al. 2014, AlMaadeed et al. 2014b). The improvement in composite modulus is an expected outcome because the reinforcement effect caused by the wood flour addition (Eshraghi et al. 2016). It is clearly seen that the composite modulus increased with the wood flour loading. Similar behaviour was also observed by AlMaadeed and coworkers in composites based on low density polyethylene filled with date palm wood powder (AlMaadeed et al. 2014a). This dependence can be analyzed using the rule of mixtures (Jones 1999) expressed by the following equations: 
Upper bound

$$
E_{C}=E_{m} V_{m}+E_{f} V_{f} \quad \text { (Equation 1) }
$$

Lower bound

$$
E_{C}=\frac{E_{m} E_{f}}{\left(V_{m} E_{f}+V_{f} E_{m}\right)}
$$

where $E_{c}, E_{m}$ and $E_{f}$ are the tensile modulus of the composites, matrix and filler, respectively; $V_{m}$ and $V_{f}$ are the volume fractions of matrix and filler.

The predicted composite tensile modulus using the rule of mixtures is shown in Figure 1. When the wood flour addition is $20 \mathrm{wt} \%$ both composites with and without coupling agent showed tensile modulus closer to the lower bound. However, when the wood flour content is $40 \mathrm{wt} \%$ the composites showed a different trend and the modulus are closer to the upper bound, which may be associated with the higher reinforcement effect caused by the wood flour addition at higher loadings.

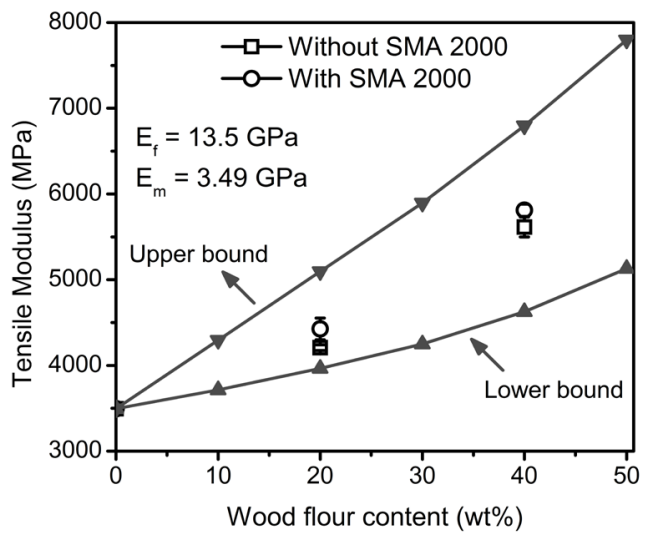

Figure 1. Theoretical and experimental tensile modulus of rPS/wood flour composites.

Figure 2 shows that the impact strength decreased with the wood flour loading. The poor interfacial adhesion between filler and matrix may cause micro-cracks during the impact test that can easily propagate in composite without coupling agent (Bengtsson et al. 2007, Nygård et al. 2008). These micro-cracks decrease the composite impact strength. When the wood flour addition increases more weak interfaces between wood flour and rPS are create, resulting in more stress concentration and more crack initiation points, and as a consequence the impact strength significantly decrease (Bengtsson et al. 2007). The stiff wood fibers also reduce the polymer chain mobility, thereby reducing the composite ability to absorb energy during fracture propagation, which leads to lower impact strength values (Nygård et al. 2008, Poletto et al. 2012). On the other hand, composites with coupling agent exhibited better impact strength that the composites without SMA 2000. The coupling agent promote better interfacial bonding better filler and matrix and also improve the wood flour dispersion in matrix, leading to a more uniform dispersion of the applied stress during the impact test (Nygård et al. 2008, Poletto et al. 2012). So, more energy for debonding and fiber pull-out is required and the composite impact strength increases (Nygård et al. 2008). García-García and coworkers also observed an improvement in the impact strength after the addition of polypropylene grafted maleic anhydride in composites of polypropylene reinforced by coffee ground powder (García-García et al. 2015). The authors attribute this improvement to the strong interactions among particle-polymer at the interface. 


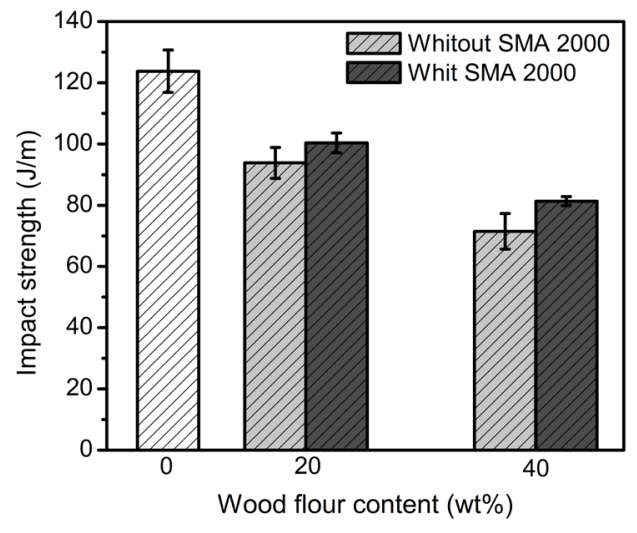

Figure 2. Composite impact strength as a function of wood flour loading.

\section{Morphological characterization}

Figure 3 shows the SEM micrograph of composite without and with coupling agent at $40 \mathrm{wt} \%$ of wood flour. The fracture surface of non-treated composite in Figure 3(a) indicated the presence of pulled-out traces and bigger gaps between the wood flour and matrix, which is evidence of weak interfacial adhesion at the interface (Kim et al. 2007, Poletto et al. 2014), corroborating the lower mechanical properties observed for composites without SMA 2000.

The SEM micrograph of the composite treated with SMA 2000, Figure 3(b) show that the fibers were involved by the matrix. This result demonstrated that the coupling agent provides strong interfacial adhesion (Poletto et al. 2014, Turku et al. 2017). In addition, the good wetting between the wood flour and rPS matrix for treated composites shown in Figure 3(b) corroborates the higher mechanical properties observed in Table 1, since the applied stress can be better transfer from the matrix to the reinforced fibers improving the composite performance (Poletto et al. 2014, El-Sabbagh 2014, Naghmouchi et al. 2015).
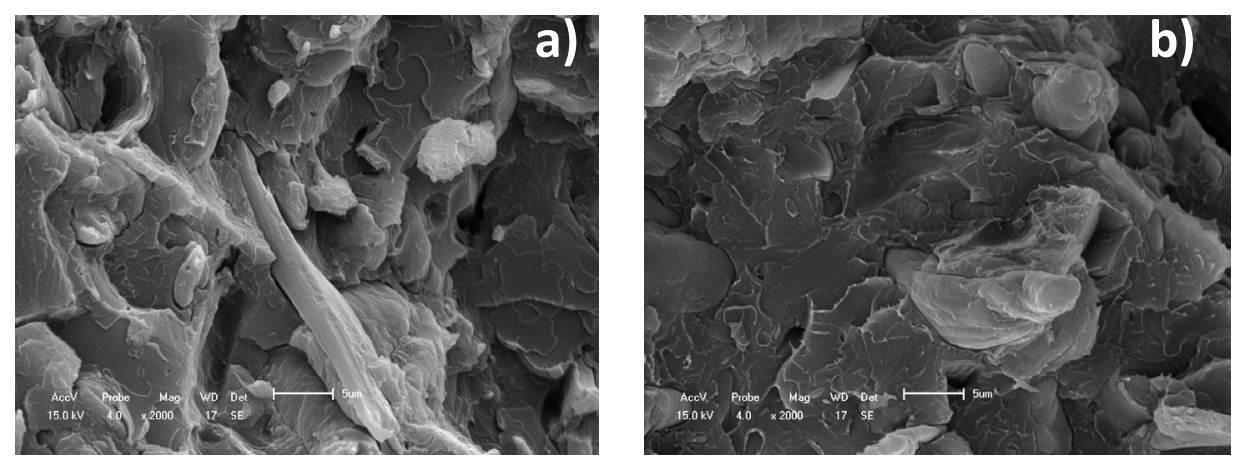

Figure 3. SEM micrographs of the composites fracture surfaces without (a) and with (b) coupling agent. 


\section{Dynamic mechanical properties}

The storage modulus is the most important property to assess the load bearing capacity of a composite material (Mohanty et al. 2006, Hameed et al. 2007). The addition of wood flour caused an increasing on the storage modulus of rPS matrix, as can be seen in Figure 4 (a). This may be associated with the increase in the stiffness of the matrix due the reinforcement effect caused by the wood flour (Mohanty et al. 2006, Ornaghi Jr. et al. 2010). The storage modulus for treated composites is higher than the untreated composites. The coupling agent promotes better interfacial adhesion between filler and matrix, as observed in SEM micrographs (Figure 3(b), which result in higher storage modulus.
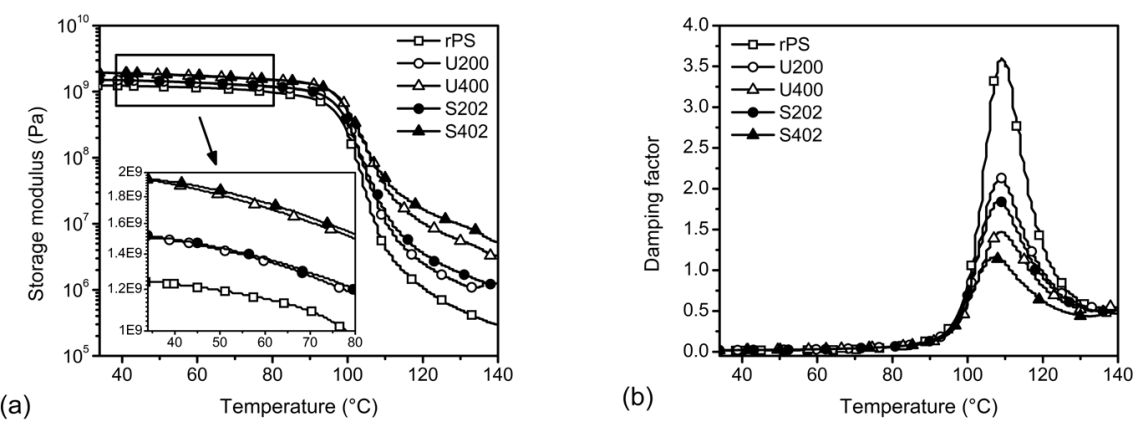

Figure 4. Storage modulus (a) and damping factor (b) of the samples studied.

The effectiveness of filler on the storage modulus of the composites can be represented by a coefficient $C$ given by the following equation (Idicula et al. 2005, Paul et al. 2010):

$$
C=\frac{\left(E_{g}^{\prime} / E_{r}^{\prime}\right) \text { comp }}{\left(E_{g}^{\prime} / E_{r}^{\prime}\right) \text { matrix }}
$$

where $E_{g}^{\prime}$ and $E_{r}^{\prime}$ are the storage modulus values in the glassy and rubbery regions, respectively. The $E^{\prime}$ values measured at 50 and $120^{\circ} \mathrm{C}$ were employed as the $E_{\mathrm{g}}^{\prime}$ and $E_{\mathrm{r}}^{\prime}$, respectively. A high $C$ value indicates that the filler is less effective (Idicula et al. 2005, Paul et al. 2010). The values obtained for different composites are given in Table 2. It can be observed the $\mathrm{C}$ values decreased with the wood flour addition, demonstrating that wood flour is an effective reinforcement for the composites, in agreement with the results presented in Table 1 for tensile and flexural modulus. When the coupling agent is used the filler becomes more effective. Hence, the sample with maximum effectiveness is the treated composite with $40 \mathrm{wt} \%$ of wood flour, where the maximum stress transfer between the filler and matrix takes place.

Table 2. Variation of $C$ factor and adhesion factor for the composites studied.

\begin{tabular}{|l|c|c|}
\hline Sample & $\boldsymbol{C}$ factor & $\boldsymbol{A}$ factor \\
\hline U200 & 0,952 & $-0,294$ \\
\hline U400 & 0,880 & $-0,386$ \\
S202 & 0,930 & $-0,389$ \\
\hline S402 & 0,855 & $-0,514$ \\
\hline
\end{tabular}


The material damping properties give the balance between the elastic phase and viscous phase in a polymeric structure (Mohanty et al. 2006, Hameed et al. 2007, Sreekumar et al. 2011). In composites, damping $(\tan \delta$ ) is influenced by fillers incorporation (Mohanty et al. 2006). The mechanical damping values for the composites are lower than those for the rPS, as seen in Figure 4(b). It was found that as the amount of wood flour in the composite increases, the damping value decreases. The incorporation of wood flour also reduces the height of the damping peak. As the wood flour content increases, the system becomes more rigid, as a result, the restriction of the polymer chains increases, and damping values are reduced.

The damping peak for treated composites was lower than the rPS and untreated composites. The energy dissipation will occur in the polymer matrix at the interface and a strong interface is characterized by less energy dissipation (Mohanty et al. 2006, Hameed et al. 2007). Thus, the damping peak of the untreated composite was lower in comparison to the neat polystyrene and higher when compared with the treated composites. This behavior demonstrates that a composite material with poor interfacial bonding between the filler and matrix will tend to dissipate more energy, showing a higher damping peak in comparison to material with a strongly bonded interface (Manikandan Nair et al. 2001).

The adhesion factor, $A$, proposed by Kubát et al. (1990), can be used to better investigate the effects of different surface treatments on the interfacial adhesion between filler and matrix. The adhesion factor can be expressed in terms of the relative damping of the composite and the polymer matrix and the volume fraction of the filler as follows (Kubát et al. 1990):

$$
A=\left[\left(\tan \delta_{c}-\tan \delta_{m}\right) /\left(1-V_{f}\right)\right]-1 \quad \text { (Equation 4) }
$$

where the subscripts $c$ and $m$ denote composite and matrix, respectively, and $\mathrm{V}_{\mathrm{f}}$ is the corresponding volume fraction of the filler. At high levels of interface adhesion, the molecular mobility surrounding the filler is reduced, and this reduces the $\tan \delta_{c}$ values and consequently the $A$ values. Thus, a low value for the adhesion factor $A$ suggests improved interactions at the matrix-filler interface (Kubát et al. 1990, Correa et al. 2007).

The adhesion factor values for the treated and untreated composites are shown in Table 2. The treated composites showed lower adhesion factor values, which indicates the higher adhesion promote by the usage of coupling agent. Probably the sufficiently lower molecular weight of SMA2000 may promote better diffusion in the rPS matrix which may lead to entanglements with the polystyrene matrix associated with the formation of chemical bonds between the maleic anhydride groups in the coupling agent and the hydroxyl groups present on the wood flour that may result in higher mechanical and dynamic mechanical properties observed for treated composites.

\section{CONCLUSIONS}

The results indicated that the mechanical and dynamic mechanical properties decrease with the wood flour loading, for composites without coupling agent. However, when the coupling agent was used all the properties evaluated increased, as a result of the better interfacial adhesion between filler and polymer matrix. SEM micrographs of the treated composites indicated strong bonding and good wetting between wood flour and rPS matrix, while for untreated composited were observed gaps and fiber pull-out. The parameters obtained through dynamic mechanical analysis, such as, $C$ factor and adhesion factor, are in agreement with the results obtained in mechanical properties, which demonstrate that valuable information about the composite performance can be obtained using dynamic mechanical analysis. The improvement in the properties evaluated after coupling agent addition may be attributed to the strong interfacial adhesion caused by the formation of chemical bonds between the maleic anhydride groups of the coupling agent with the hydroxyl groups of wood flour and also between the entanglements between the polystyrene matrix and the polystyrene groups of the coupling agent. 


\section{ACKNOWLEDGEMENTS}

The author is grateful to Associação dos Recicladores Serrano de Caxias do Sul, Madarco S.A. and Sartomer Company for supplying materials.

\section{REFERENCES}

AlMaadeed, M.A.; Nógellová, Z.; Mičušík, M.; Novák, I.; Kruppa, I. 2014a. Mechanical, sorption an adhesive properties of composites based on low density polyethylene filled with date palm wood power. Materials and Design 53: 29-37.

AlMaadeed, M.A.; Nógellová, Z.; Janigová, I.; Kruppa, I. 2014b. Improved mechanical properties or recycled linear low-density polyethylene composites filled with date palm wood power. Materials and Design 58: 209-216.

Bengtsson, M.; Le Baillif, M.; Oksman, K. 2007. Extrusion and mechanical properties of highly filled cellulose fibre-polypropylene composites. Composites Part A 38: 1922-1931.

Correa, C.A.; Razzino, C.A.; Hage Jr., E. 2007. Role of maleated coupling agents on the interface adhesion of polypropylene-wood composites. Journal of Thermoplastic Composite Materials 20: 323-339.

El-Sabbagh, A. 2014. Effect of coupling agent on natural fibre/polypropylene composites on mechanical and thermal behaviour. Composites Part B 57: 126-135.

Eshraghi, A.; Khademieslam, H.; Ghasemi, I. 2016. Effect of weathering on physical and mechanical properties of hybrid nanocomposite based on polyethylene, woodflour and nanoclay. Maderas. Ciencia y tecnología 18: 617-626.

García-García, D.; Carbonell, A.; Samper, M.D.; García-Sanoguerra, D.; Balart, R. 2015. Green composites based on polypropylene matrix and hydrophobized spend coffee ground (SCG) powder. Composites Part B 78: 256-265.

Güleç, T.; Tufan, M.; Akbaş, S. 2017. Insect damage wood as source of reinforcing filler for thermoplastic composite. Maderas. Ciencia y tecnología 19: 75-86.

Hong, H.; Liao, H.; Zhang, H.; He, H.; Liu, T.; Jia, D. 2014. Significant improvement in performance of recycled polyethylene/wood flour composites by synergistic compatibilization at multiscale. Composites Part A 64: 90-98.

Idicula, M; Malhotra, S.K.; Joseph, K.; Thomas, S. 2005. Dynamic mechanical analysis of randomly oriented intimately mixed short banana/sisal hybrid fibre reinforced polyester composites. Composites Science and Technology 65: 1077-1087.

Jones, R.M. 1999. Mechanics of composite materials. $2^{\text {nd }}$ ed., Taylor and Francis, Philadelphia.

Khonsari, A.; Taghiyari, H.R.; Karimi, A.; Tajvidi, M. 2015. Study on the effect of wood flour geometry on physical and mechanical properties of wood-plastic composites. Maderas. Ciencia y tecnología 17: 545-558.

Kim, H.S.; Lee, B.H.; Choi, S.W.; Kim, S.; Kim, H.J. 2007. The effect of types of maleic anhydride-grafted polypropylene (MAPP) on the interfacial adhesion properties of bio-flour-filled polypropylene composites. Composites Part A 38: 1473-1482.

Kord, B.; Malekian, B.; Yousefi, H.; Najafi, A. 2016. Preparation and characterization of nanofibrillated cellulose/poly (vinylalcohol) composite films. Maderas. Ciencia y tecnología 18: 743752.

Kubát, J.; Rigdahl, M.; Welander, M. 1990. Characterization of interfacial interactions in high density polyethylene filled with glass spheres using dynamic-mechanical analysis. Journal of Applied 
Polymer Science 39: 1527-1539.

Liu, R.; Peng, Y.; Cao, J.; Chen, Y. 2014. Comparison on properties of lignocellulosic flour/ polymer composites by using wood, cellulose, and lignin flours as fillers. Composites Science and Technology 103: 1-7.

Manikandan Nair, K.C.; Sabu, T; Groeninckx, G. 2001. Thermal and dynamic mechanical analysis of polystyrene composites reinforced with short sisal fibres. Composites Science and Technology 61: 2519-2529.

Mohanty, S.; Verma, S.K.; Nayak, S.K. 2006. Dynamic mechanical and thermal properties of MAPE treated jute/HDPE composites. Composites Science and Technology 66: 538-547.

Nachtigall, S.M.B.; Cerveira, G.S.; Rosa, S.M.L. 2007. New polymeric-coupling agent for polypropylene/wood-flour composites. Polymer Testing 26: 619-628.

Nafchi, H.R.; Abdouss, M.; Najaf, S.K.; Gargari, R.M.; Mazhar, M. 2015. Effects of nanoclay particles and oxidized polypropylene polymers on improvement of the termal properties of wood plastic composite. Maderas. Ciencia y tecnología 17: 45-54.

Naghmouchi, I.; Espinach, F.X.; Mutjé, P.; Boufi, S. 2015. Polypropylene composites based on lignocellulosic fillers: how the filler morphology affects the composite properties. Materials and Design 65: 454-461.

Najafi, S.K. 2013. Use of recycled plastics in wood plastic composites - A review. Waste Management 33: 1898-1905.

Nygård, P.; Tanem, B.S.; Karlsen, T.; Brachet, P.; Leinsvang, B. 2008. Extrusion-based wood fibre-PP composites: wood powder and pelletized wood fibre - a comparative study. Composite Science and Technology 68: 3418-3424.

Ornaghi Jr., H.L.; Bolner, A.S.; Fiorio, R.; Zattera, A.J.; Amico, S.C. 2010. Mechanical and dynamic mechanical analysis of hybrid composites molded by resin transfer molding. Journal of Applied Polymer Science 118: 887-896.

Ou, R.; Xie, Y.; Wolcott, M.P.; Sui, S.; Wang, Q. 2014. Morphology, mechanical properties, and dimensional stability of wood particle/high density polyethylene composites: effect of removal of wood cell wall composition. Materials and Design 58: 339-345.

Paul, S.A.; Sinturel, C.; Joseph, K.; Gem Mathew, G.D.; Pothan, L.A.; Sabu, T. 2010. Dynamic mechanical analysis of novel composites from commingled polypropylene fiber and banana fiber. Polymer Engineering and Science 50: 384-395.

Poletto, M.; Zeni, M.; Zattera, A.J. 2012. Effects of wood flour addition and coupling agent content on mechanical properties of recycled polystyrene/wood flour composites. Journal of Thermoplastic Composite Materials 25: 821-833.

Poletto, M.; Zattera, A.J.; Santana, R.M.C. 2014. Effect of natural oils on the stability and degradation kinetics of recycled polypropylene wood flour composites. Polymer Composites 10: 19351942.

Punyamurthy, R.; Sampathkumar, D.; Ranganagowda, R.P.; Bennehalli, B.; Badyankal, P.; Venkateshappa, S.C. 2014. Surface modification of abaca fiber by benzene diazonium chloride treatment and its influence on tensile properties of abaca fiber reinforced polypropylene composites. Ciência \& Tecnologia dos Materiais 26: 142-149.

Spoljaric, S.; Genovese, A.; Shanks, R.A. 2009. Polypropylene-microcrystalline cellulose composites with enhanced compatibility and properties. Composites Part A 40: 791-799.

Sreekumar, P.A.; Thomas, P.S; Saiter, J.M.; Unnikrishnan, G.; Sabu, Ts. 2011. Viscoelastic and thermal properties of eco-friendly composites fabricated by resin transfer molding. Journal of 
Reinforced Plastics and Composites 30: 1509-1516.

Teuber, L.; Osburg, V.S.; Toporowski, W.; Militz, H.; Krause, A. 2016. Wood polymer composites and their contribution to cascading utilization. Journal of Cleaner Production 110: 9-15.

Tufan, M.; Akbaş, S.; Aslan, M. 2016. Decay resistance, thermal degradation, tensile and flexural properties of sisal carbon hybrid composites. Maderas. Ciencia y tecnología 18: 509-606.

Turku, I.; Keskisaari, A.; Kärki, T.; Puurtinen, A.; Marttila, P. 2017. Characterization of wood plastic composites manufactured from recycled plastic blends. Composite Structures 161: 469-476. 